assays of stable isotope tracers. Anal. Chem., 45: 2063 (1973).

6. Hsia, Y. E., Scully, K. J., and Rosenberg, L. E.: Defective propionate carboxylation in ketotic hyperglycinemia. Lancet, $i$ : 757 (1969).

7. Huennekens, F. M., Ho, P. P. K., and Scrimgeour, K. G.: Preparation and properties of "active formaldehyde" and "active formate." Methods Enzymol., 6: 806 (1963).

8. Lowry, O. H., Rosebrough, N. J., Farr, A. L., and Randall, R. J.: Protein measurement with the Folin phenol reagent. J. Biol. Chem., 193: 265 (1951).

9. Mahoney, M. J., and Rosenberg, L. E.: Uptake of $\alpha$-amino isobutyric acid by cultured human fibroblasts. Biochim. Biophys. Acta, 219: 500 (1970).

10. Mamer, O. A., Crawhall, J. C., and Tjoa, S. S.: The identification of urinary acids by coupled gas chromatography-mass spectrometry. Clin. Chim. Acta, 32: 171 (1971).

11. Menkes, J. H.: Idiopathic hyperglycinemia: Isolation and identification of three previously undescribed urinary ketones. J. Pediat., 69: 413 (1966).

12. Nyhan, W. L., Ando, T., Rasmussen, K., Wadlington, W., Kilroy, A. W. Cottom, D., and Hull, D.: Tiglicaciduria in propionicacid-

Copyright (c) 1974 International Pediatric Research Foundation, Inc. aemia. Biochem. J., 126: 1035 (1972).

13. Rosenberg, L. E., Lilljeqvist, A. C., and Hsia, Y. E.: Methylmalonic acidemia: An inborn error leading to metabolic acidosis, long chain ketonuria and intermittent hyperglycinemia. New Engl. J. Med., 278: 1319 (1968).

14. Schirch, L.: Serine transhydroxymethylase. Methods Enzymol., 17: 335 (1971).

15. Scrimgeour, K. G., and Huennekens, F. M.: N5, N10-Methylene tetrahydrofolic dehydrogenase. Methods Enzymol., 6: 368 (1963).

16. Grand Island Biological Co., Chagrin Falls, Ohio.

17. This work was supported in part by United States Public Health Service Grant no. AM 15531 and the Ranken Jordan Trust Fund. The authors wish to thank Mrs. Liang Chu Daniel for her technical assistance and Mrs. Sabra Lovejoy for her aid in preparing this manuscript.

18. Requests for reprints should be addressed to: R. E. Hillman, M.D., Division of Medical Genetics, Department of Pediatrics, St. Louis Children's Hospital, 500 S. Kingshighway, St. Louis, Mo. 63110 (USA).

19. Accepted for publication July 15,1974 .

Printed in U.S.A.

Pediat. Res. 8: 945-950 (1974)

Adenosine arabinoside brain congenital disease

\title{
Effect of the Antiviral Drug, Cytosine Arabinoside, on the Developing Nervous System
}

\author{
STEPHEN ASHWAL, MILTON FINEGOLD, IRVING FISH, GLEB BUDZILOVICH, AND \\ PHILIP A. BRUNELL (17) \\ Departments of Pediatrics, Pathology, and Neurology, New York University School of Medicine, \\ New York, New York, USA
}

\section{Extract}

Cytosine arabinoside (which is used to treat congenital viral infections) produced neurologic and retinal damage in infant mice. Station and gait abnormalities could be related to hypoplasia and marked microscopic changes in the cerebellum of treated animals. These, as well as microscopic changes in the retina, appeared to be irreversible. The damage produced appeared to result from destruction of primordial cells during a critical period of differentiation.

\section{Speculation}

The potential for producing neurologic and other damage by treatment with DNA inhibitors during this period of rapid growth must be considered when contemplating the use of these DNA inhibitors for treatment of congenital virus infections.

The treatment of newborn infants suffering from congenital virus infections with inhibitors of DNA synthesis has been reported $(2,4,7,8,10)$. Therapy has been based on the observations that such compounds as iododexoxyuridine, adenosine arabinoside (Ara-A), or cytosine arabinoside (Ara-C) inhibit these DNA viruses in vitro (12). In vivo, however, these compounds may restrict host DNA synthesis in uninfected as well as in virus-infected cells. This is of particular concern in newborn infants whose cells are undergoing active division and differentiation.

The potential effect of DNA inhibitors on the developing central nervous system (CNS) of the neonate is of particular concern because of the devastating consequences that might ensue if functions were permanently impaired. It has been shown, moreover, that cellular growth and differentiation continues after birth in the human $(5,13)$. Ara-C, which has been used to treat infants with congenital viral infections, was found to have a deleterious effect on both function and structure of the mouse nervous system. The implication of these observations for treatment of newborn infants with congenital viral infections with DNA inhibitors is considered in this light.

\section{METHODS}

Experiments were carried out using 57 litters each consisting of 8 newborn CFW (14) mice. Members of a single mouse litter were injected subcutaneously with $0.03 \mathrm{cc}$ of either normal saline or Ara-C (15). The drug was administered in single doses of $50 \mathrm{mg} / \mathrm{kg}$ which were given on 3 alternate days beginning on the 2nd day of life. Mice were observed for neurologic or 
other abnormalities and weighed at regular intervals. At 1, 3, and 6 weeks of age, predetermined litters were killed and weighed. The brains were weighed and then dissected into cerebrum, brain stem, and cerebellum. These separate regions were weighed at this time. Predesignated litters of treated and control mice were killed and their organs were prepared for pathologic examination.

In order to detect infectious agents that might have been activated by immunosuppression and responsible for the observed results, brain homogenates of a few severely affected animals were tested for the presence of microbial organisms. PPLO, tryptic soy and thioglycolate broth, human embryonic lung fibroblasts, and suckling mice were inoculated with this material. Each mouse was inoculated both intraperitoneally and intracerebrally with homogenate. Two passages were made in mice and tissue culture. No viral agents or significant bacterial agents were recovered.

\section{RESULTS}

\section{EFFECT ON HAIR GROWTH AND MORTALITY}

The difference in hair growth between treated and control animals was obvious as early as 1 week of age. The more

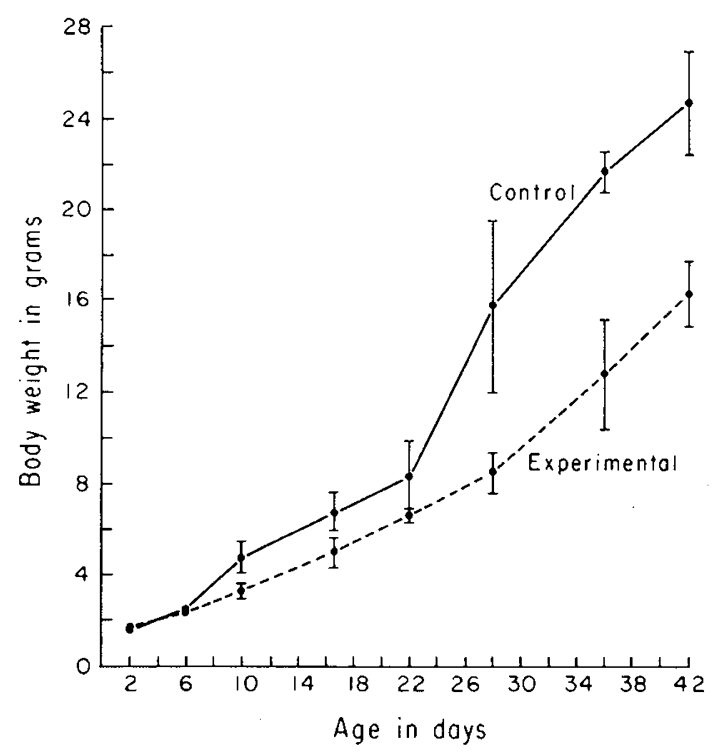

Fig. 1. Mean weights of cytosine arabinoside recipients compared with control mice. luxuriant hair growth in control animals was apparent as long as 4-5 weeks after treatment had been completed.

The mortality rate of control newborn animals was $14 \%$ during the course of the observation period, whereas that rate in Ara-C recipients was $40 \%$.

\section{EFFECTS ON BODY AND ORGAN GROWTH}

Weight determinations revealed a consistent retardation of growth of Ara-C-treated animals. The difference was apparent as early as the 10th day of life and increased with time (Fig. $1)$. Both total and regional brain weights were lower in the treated group (Table 1).

The relative reduction of cerebellar size was readily appreciated grossly (Fig. 2). When the ratio of brain region to total body weight was compared, only the cerebellum region was lower in treated than control mice. In contrast, the ratios of brain stem or cortex to total brain weight were similar in the treated and control mice (Table 1). Cerebellum to total brain weight ratios were lower in treated mice, a difference that increased with time (Fig. 3).

\section{EFFECTS ON MICROSCOPIC ANATOMY}

Brain. Microscopic examination of the brain revealed that in all treated animals, development of the cerebellar folia was

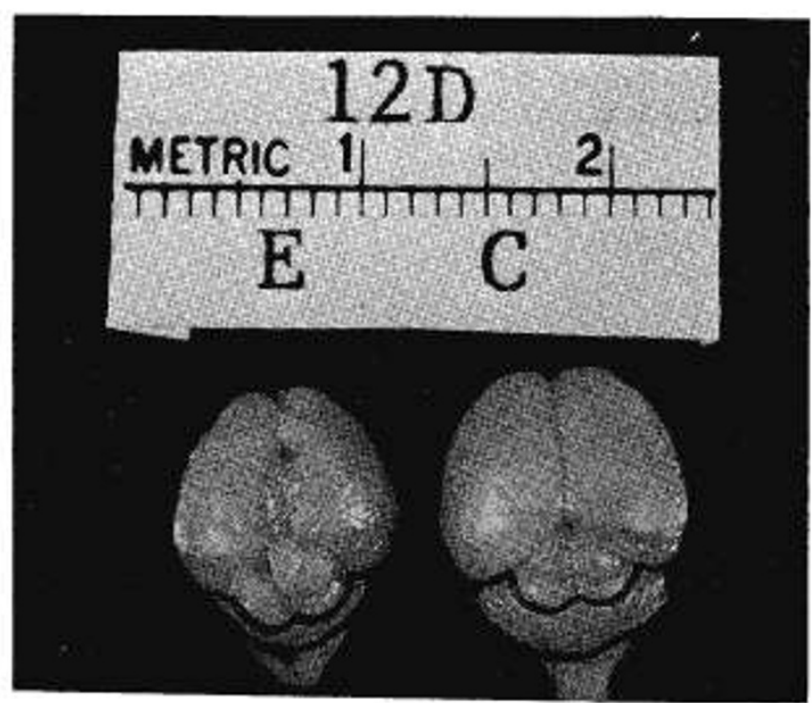

Fig. 2. There is a marked and diffuse diminution in size of cerebellum in the treated animal $(E)$ as compared with the control $(C)$. The cerebellum is outlined in ink. The cerebral hemispheres show only a slight reduction and the corpora quadrigemina are unaltered.

Table 1. Age of mice

\begin{tabular}{|c|c|c|c|c|c|c|}
\hline & \multicolumn{2}{|c|}{1 Week } & \multicolumn{2}{|c|}{2 Weeks } & \multicolumn{2}{|c|}{6 Weeks } \\
\hline & Control & Treated & Control & Treated & Control & Treated \\
\hline $\mathrm{TM}, \mathrm{mg}$ & $3,100 \pm 600$ & $2,400 \pm 700$ & $9,000 \pm 1,500$ & $5,700 \pm 1.3$ & $24,500 \pm 2,800$ & $16,000 \pm 4,600$ \\
\hline $\mathrm{TB}, \mathrm{mg}$ & $163 \pm 255$ & $14.77 \pm 28.5$ & $344 \pm 20$ & $274.4 \pm 41.7$ & $396.6 \pm 25$ & $334.7 \pm 31.9$ \\
\hline $\mathrm{CO}, \mathrm{mg}$ & $125 \pm 22.6$ & $114.3 \pm 21.8$ & $247 \pm 23$ & $217.2 \pm 40.5$ & $291.1 \pm 20.1$ & $260.3 \pm 27.8$ \\
\hline $\mathrm{BS}, \mathrm{mg}$ & $23 \pm 5$ & $21.2 \pm 6.5$ & $51 \pm 8.9$ & $40.3 \pm 14.1$ & $58.9 \pm 12.9^{-}$ & $52.5 \pm 19.2$ \\
\hline $\mathrm{CE}, \mathrm{mg}$ & $13 \pm 5$ & $12.7 \pm 6.6$ & $38.5 \pm 5.6$ & $16.9 \pm 17.3$ & $48.2 \pm 7.0$ & $22.4 \pm 4.4$ \\
\hline $\mathrm{CO} / \mathrm{TM}$ & $0.040 \pm 0.006$ & $0.049 \pm 0.011$ & $0.029 \pm 0.005$ & $0.041 \pm 0.008$ & $0.011 \pm 0.002$ & $0.017 \pm 0.007$ \\
\hline $\mathrm{BS} / \mathrm{TM}$ & $0.007 \pm 0.002$ & $0.009 \pm 0.004$ & $0.006 \pm 0.001$ & $0.007 \pm 0.003$ & $0.002 \pm 0.001$ & $0.003 \pm 0.001$ \\
\hline CE/TM & $0.004 \pm 0.0016$ & $0.005 \pm 0.0023$ & $0.004 \pm 0.001$ & $0.003 \pm 0.001$ & $0.002 \pm 0.004$ & $0.0015 \pm 0.0006$ \\
\hline $\mathrm{CO} / \mathrm{TB}$ & $0.773 \pm 0.04$ & $0.775 \pm 0.04$ & $0.741 \pm 0.03$ & $0.787 \pm 0.07$ & $0.735 \pm 0.04$ & $0.78 \pm 0.04$ \\
\hline $\mathrm{BS} / \mathrm{TB}$ & $0.147 \pm 0.02$ & $0.141 \pm 0.04$ & $0.151 \pm 0.026$ & $0.147 \pm 0.05$ & $0.148 \pm 0.03$ & $0.156 \pm 0.04$ \\
\hline $\mathrm{CE} / \mathrm{TB}$ & $0.086 \pm 0.04$ & $0.082 \pm 0.04$ & $0.105 \pm 0.02$ & $0.056 \pm 0.02$ & $0.122 \pm 0.01$ & $0.066 \pm 0.01$ \\
\hline
\end{tabular}

\footnotetext{
${ }^{1}$ Weight of treated and control animals and organs at intervals following Ara-C treatment. The weights are abbreviated as follows. TM: total
} mouse; TB: total brain; CO: cortex; BS: brain stem; CE: cerebellum. 

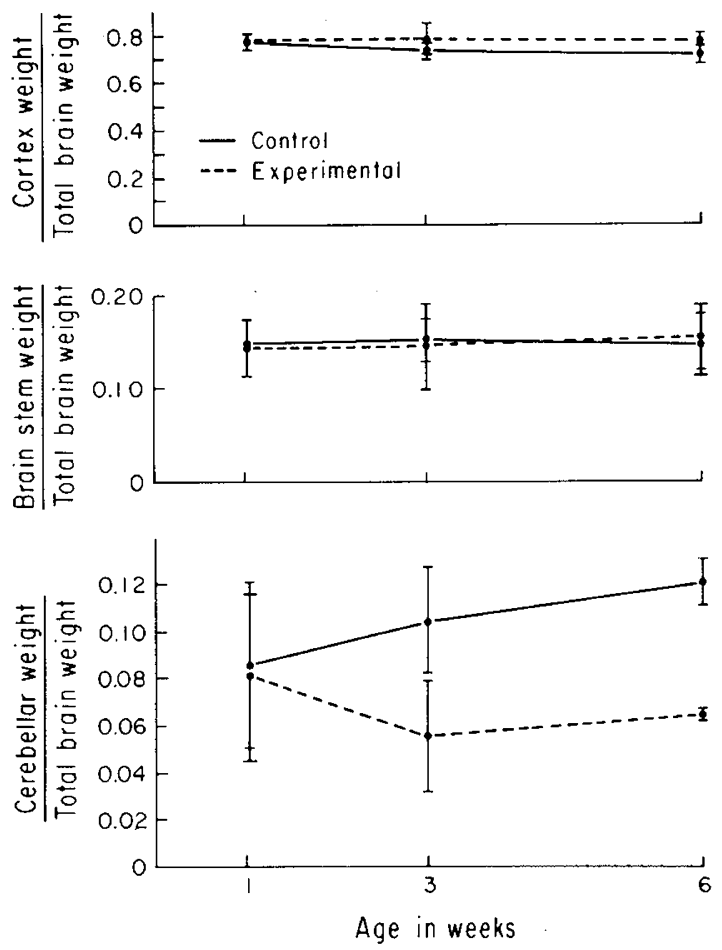

Fig. 3. The proportion of the total brain comprised by the cortex, brain stem, or cerebellum for mice who received cytosine arabincside is compared with that of untreated mice at intervals after treatment. The most striking difference is observed in the cerebellum. This region is normally the most rapidly growing during this period as indicated by the increase in proportion of total brain weight in untreated control mice.
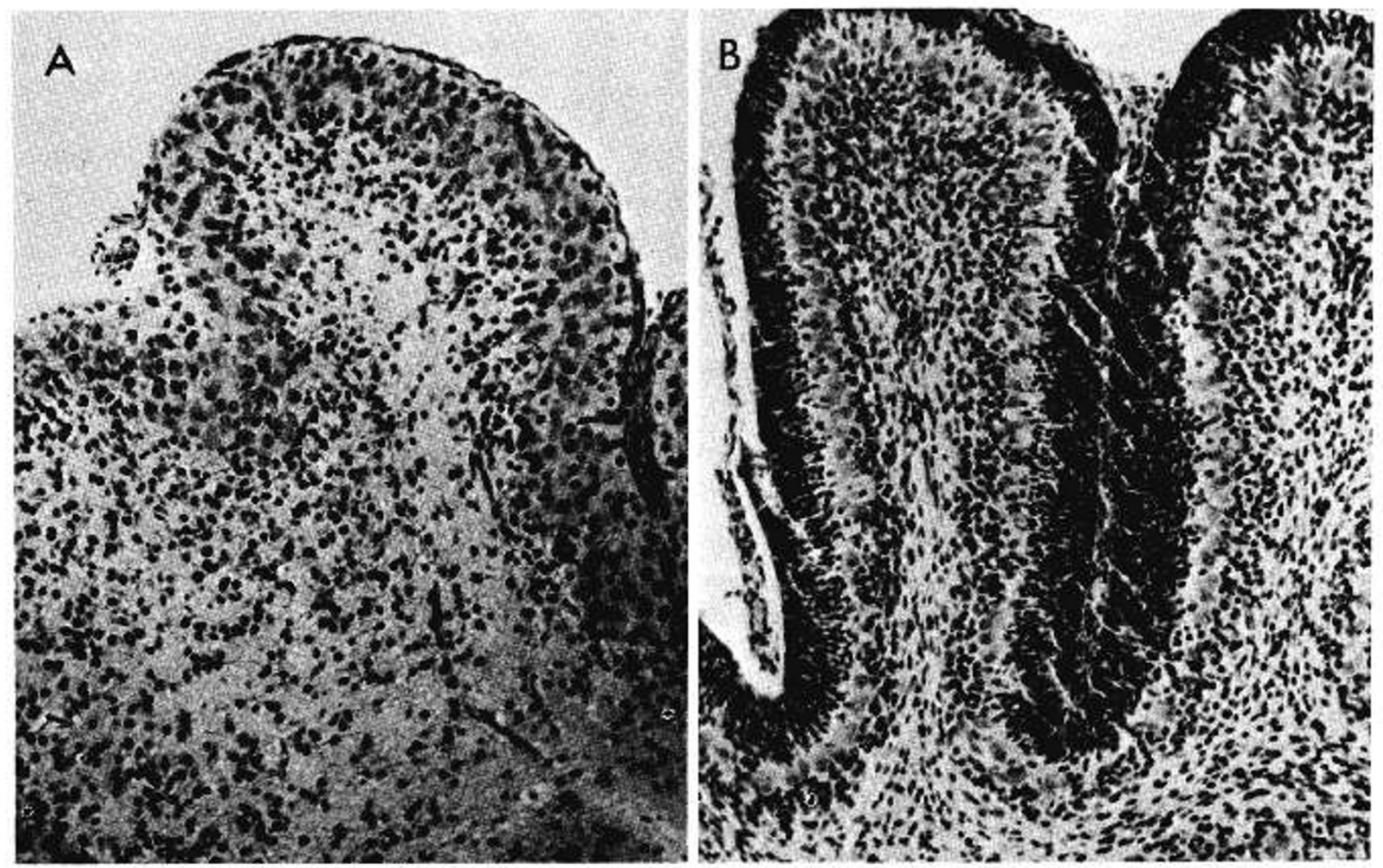

Fig. 4. At 7 days, there is severe depletion of primitive cells in the external granular cell layers. The Purkinje cells are randornly scattered throughout the hypoplastic molecular cell layer. The internal granular cell layer is distinctly underpopulated. $A$ : treated animal: $B$ : control (Nissl stain, $\times 150$ ) severely and diffusely retarded. At 7 days, there was severe depletion and focal absence of neuroblastic elements from the external germinal layer. The internal germinal cell layer was rarified and markedly underpopulated. The molecular cell layer was indistinct in both control and treated animals at this time. The Purkinje cell bodies appeared normal morphologically but in the treated animals they were dispersed in a hypoplastic molecular layer (Fig. 4).

In treated animals, at 12 days, there was now a well defined but still depleted external germinal layer. In addition, inwardly migrating primitive cells were seen singly or in small clusters within the disorganized molecular and Purkinje cell layers. At 15 days, the number of neuroblasts migrating through the molecular layer and reaching the definitive germinal cell layer continued to increase. The Purkinje cell layer remained disorganized. At 18 and 21 days, the changes in the treated animals were like those at 15 days. No external germinal cell layer was present in the control animals, the migration having been completed by 18 days. At 42 days neither an external germinal layer nor any migratory activity could be seen in the treated animals. However, the Purkinje cells remained disorganized and scattered throughout the deeper one-half to two-thirds of the molecular layer. In some areas, notably in the summits of the folia of the anterosuperior segments of the dermis, varying numbers of mature granule cells were present among the Purkinje cells, being either markedly reduced or absent in other areas (Fig. 5). The dendrites and axis cylinders of the Purkinje cells were moderately reduced in number and diameter; well developed "baskets" and tangential fibers were extremely scanty. These changes were accompanied by severe depletion of the nerve fibers in the convolutional and central white matter of the cerebellum. The dentate nucleus appeared essentially normal.

Moderate retardation of myelination was noted throughout 


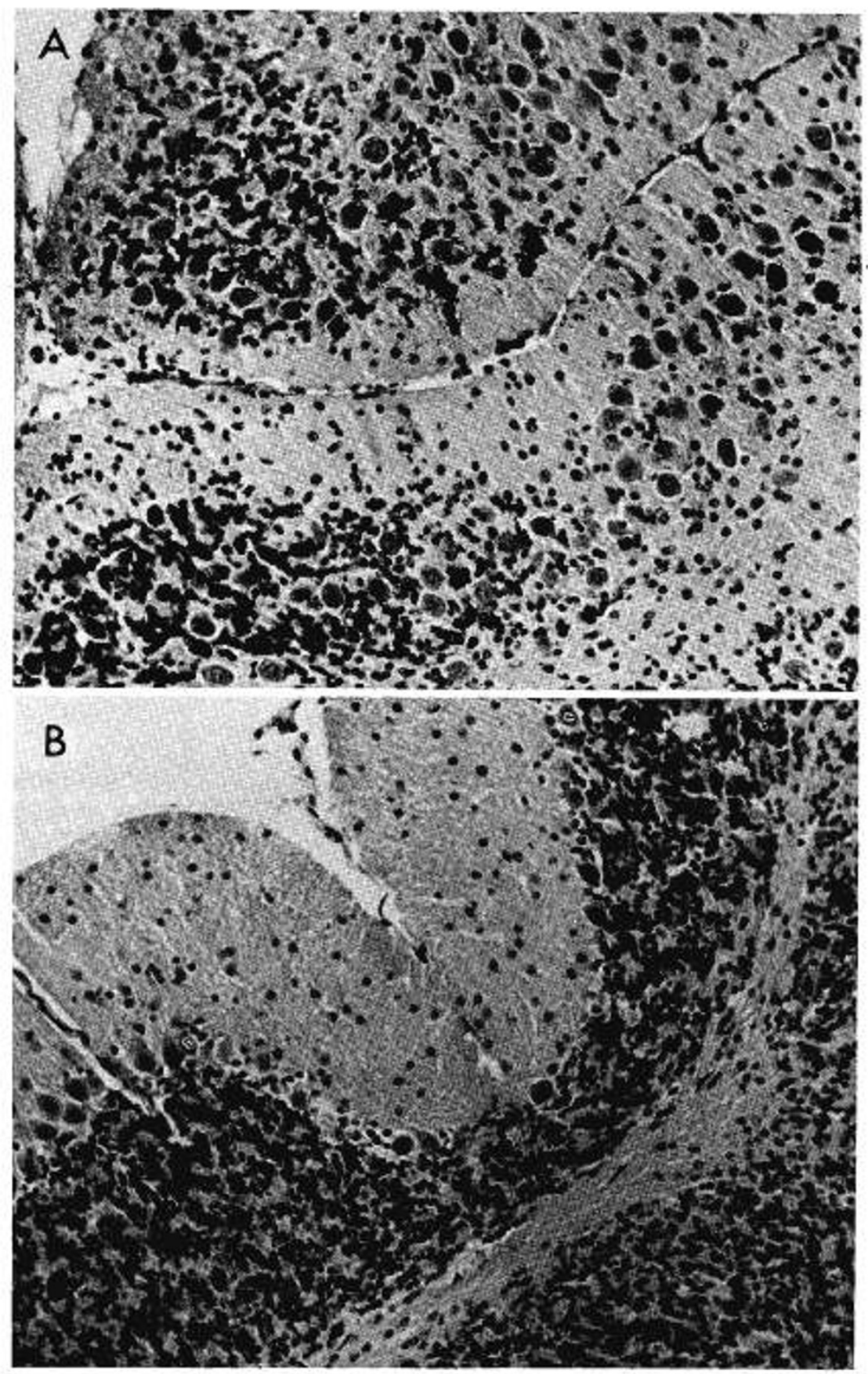

Fig. 5. At 6 weeks, an internal granular cell layer is present in some areas (left side of photo) but not others (right side of photo). The Purkinje cells are intermingled with granular cells. $A$ : treated animal; $B$ : control (hematoxylin and eosin stain, $\times 150$ ).

the cerebrum and brain stem, but no definite changes in their neuronal population could be recognized.

Eye. At 7 days the retinas of control animals were not as fully developed as at 12 days when they achieved their mature form. As early as 7 days, however, marked changes were noted in the treated mice. There was marked loss of cells in both nuclear layers with preservation of the ganglion cells. The nuclear layers were fused with the rods and cones and the cells formed rosettes rather than the palisading structure of the intact retina. A thin inner plexiform layer remained, whereas the optic nerve fiber layer was sparse and avascular (Fig. 6). Retinal dysplasia was found in two of three animals examined at day 12, one of three on day 15, two of three on day 18 , seven of nine on day 21 , and five of seven on day 42. Other ocular tissues appear unaltered by Ara-C treatment.

Hematopoietic and Lymphoid Systems. There was depletion of all the bone marrow elements on day 7 with reappearance of normal numbers of erythroid and megakaryocytic elements on day 12 and of myeloid elements on day 15. Hematopoietic activity in the liver was markedly reduced on day 7 but exceeded that in controls on days 12 and 15 . The spleen was depleted of lymphoid cells on day 6 with partial restoration apparent on day 12 and normal architecture by day 15 . Marked cortical atrophy was observed in the thymus at day 7; partial restoration was present by day 12 and normal numbers of lymphocytes were found by day 15 .

Other Organs. Treated animals had demorrstrable abnormalities in the skin, gastrointestinal epithelium, kidney, testes, and cartilage, most of which appeared to be reversible. Most impressive was mitotic arrest in the crypts of the small intestine and basal cells of the skin.

\section{EFFECTS ON FUNCTION}

There were dramatic changes in the function and behavior of the Ara-C-treated animals when compared with untreated 

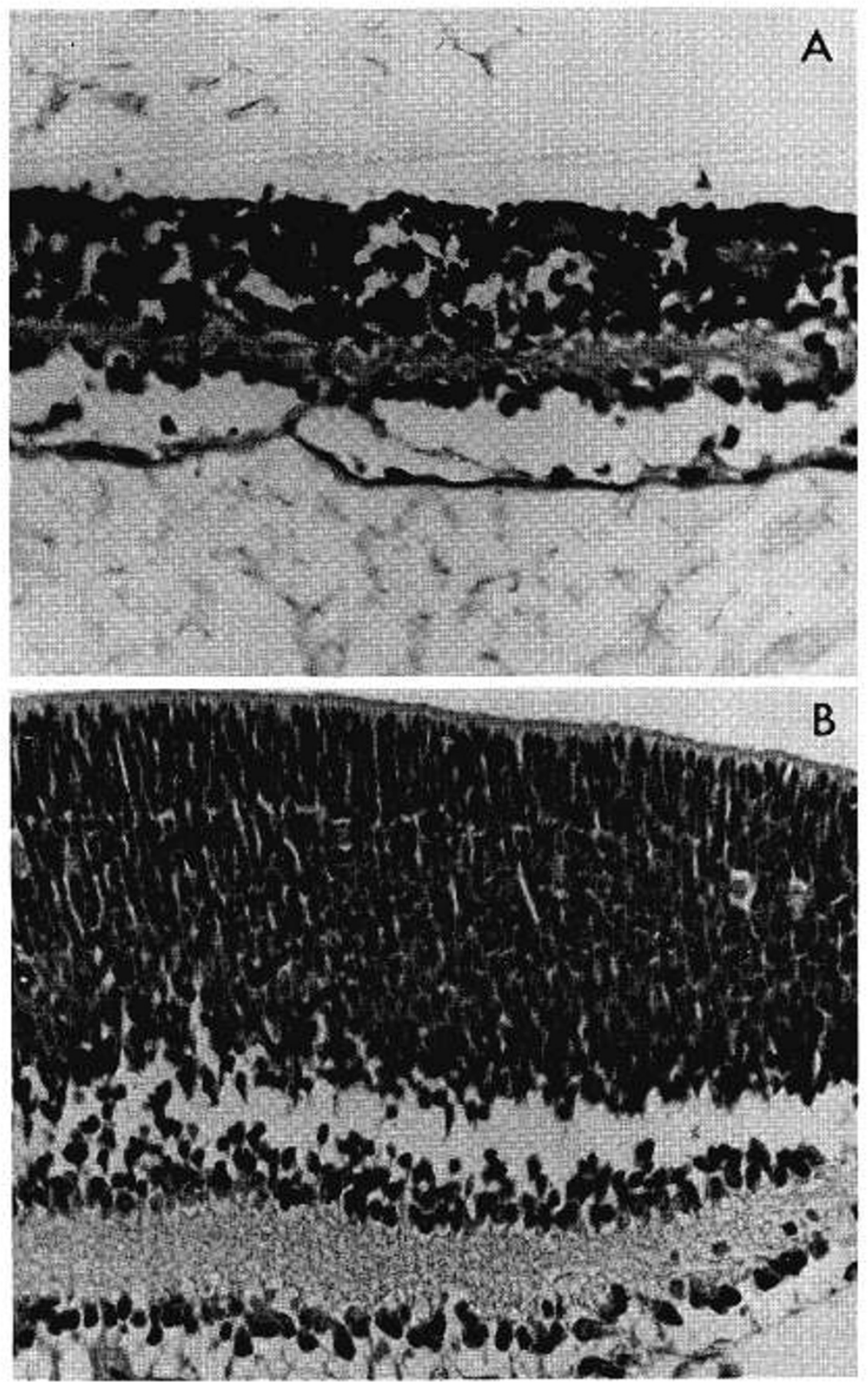

Fig. 6. Retinas of 7-day-old mice. In the control $(B)$ the nuclear layers have yet to separate and rods and cones are not distinct but cells are plentiful and form a typical palisade. Marked depletion of nuclei is apparent in the treated animal $(A)$, and rosettes are present in the thin nuclear layer. Ganglion cells and a small inner plexiform layer are present but the innermost nerve fiber layer (bottom) appears sparse and avascular. Hematoxylin and eosin stain, $\times 250$.

littermates. The treated mice had trunkal ataxia; there was a tremor of the head and extremities at rest; severe ataxia was observed on locomotion, and the ability of the animals to right themselves was impaired. All of these findings are consistent with cerebellar dysfunction, although some contribution from damage to other areas of the brain cannot be ruled out.

\section{COMMENTS}

Ara-C treatment had a deleterious effect on the nervous system of newborn mice. Anatomical and functional changes which were apparently irreversible resulted from this treatment.

Although diffuse changes were seen, the cerebellum was the most severely affected region of the brain. The selective effect on the cerebellum can probably be attributed to the fact that in the mouse, as in the human (13), the cerebellum undergoes the most rapid growth and development postnatally. Indeed, the cerebellum comprised an increasing proportion of the total brain weight during the first 6 weeks in untreated mice. In treated mice, in contrast, the contribution of cerebellum to total brain weight actually decreased during this period (Fig. 3).

Changes resulting from Ara-C treatment were observed in a variety of tissues. Sustained effects were most notable, however, in the retina and cerebellum which were in a crucial stage of development at the time of treatment. The destruction of primitive cells of the external germinal layer of the cerebellum probably prevented the later development of normal basket and granular cells of the definitive germinal cell and molecular layers of this organ. Likewise, the rosette formation in the retina probably represented an attempt to 
restore the architecture of this structure in the absence of normal precursor cells.

The observed effects of Ara-C on myelinization and dendrite formation may be even more relevant in the human than on the more dramatic changes observed in precursor cells. These processes probably continue for 3-4 years after the birth of human infants while neuronal multiplication occurs mainly in utero (5). The external germinal layer, which is a source of primitive neural elements, however, does persist in the human during the first year of life. Although experimental data exists in the rat (9) and hamster (6), studies of the effect of DNA inhibition on neurologic development of primates would certainly be indicated. Ideally, these studies should include measurements of dendritic complexity, synaptic connections, and neurochemical changes which are as yet difficult to measure but are probably important determinants of future intellectual function (5).

A meaningful comparison of dosage used in the current experiments with those used to treat infants $(4,7,8,10)$ could not be made. On a weight basis, the experimental doses were greater than those used clinically but the routes of administration and differences in metabolism between the species introduced other variables that made a meaningful comparison of doses impossible. The use of these potentially harmful drugs should be reserved for infants with life-threatening infections and the results of therapy carefully monitored for untoward effects as well as for efficacy. The treatment of asymptomatic neonates because they are excreting virus should not be recommended, especially since Ara-C and 5-iododeoxyuridine appear to be of only questionable value in eliminating cytomegalovirus or herpesvirus infections in affected infants $(4,7,8,10)$.

As newer antiviral drugs are developed, treatment with these drugs must be monitored to assess the neurologic damage that newborn infants who receive these agents might incur as a result of therapy. The rate of metabolism of these drugs in specific tissues of the neonate must also be determined. Of concern, for instance, is the relatively low level of adenosine deaminase found in the brain as compared with that found in other tissues (1). Low levels of this enzyme, which is involved in the metabolism of Ara-A, might result in slow inactivation of this compound from the brain tissue of treated neonates. Ara-A is a purine analog that is now undergoing clinical trials as an antiviral agent (2).

The possibility that Ara-C might have caused immunosuppression that resulted in activation of latent lymphocytic choriomeningitis (LCM) virus appears unlikely. Although LCM may produce degenerative changes in the germinal layer of the cerebellum (3), lymphocytic infiltration, which is usually associated with this reaction, was not observed. It was not possible, moreover, to isolate LCM from the brain tissues which were tested. The possibility that treatment of patients with DNA inhibitors may result in activation of latent viruses or may cause late damage to germinal or other tissues must also be considered. Deleterious effects of Ara-C in patients treated for zoster, presumably due to immunosuppression, have been described recently (11).

\section{SUMMARY}

Cytosine arabinoside given to mice during the first week of life produced irreversible neurologic damage. Ataxia was observed in treated mice which could be attributed to the effects of Ara-C on the cerebellum. Marked histologic changes were observed in this structure as well as in the retina. These changes appeared to result from destruction of primitive cells during a critical stage of differentiation. It is suggested that the practice of treating newborn infants with DNA inhibitors be re-evaluated.

\section{REFERENCES AND NOTES}

1. Balis, M. E.: Personal communication.

2. Ch'ien, L. T., Cannon, N. J., and Charamella, L. J., et al.: Effect of adenine arabinoside on severe herpesvirus hominus infections in man. J. Infect. Dis., 128: 658 (1973).

3. Cole, G. A., Gilder, D. H., and Monjan, A. A., et al.: Lymphocytic choriomeningitis virus: Pathogenesis of acute central nervous system disease. Fed. Proc., 30: 1831 (1971).

4. Conchie, A. F., Barton, B. W., and Tobin, J.: Congenital cytomegalovirus infection treated with idoxuridine. Brit. Med. J., 4: 162 (1968).

5. Dobbing, J.: The later growth of the brain and its vulnerability. Pediatrics, 53: 1 (1974).

6. Fischer, D. S., and Jonas, A. M.: Cerebellar hypoplasia resulting from cytosine arabinoside treatment in the neonatal hamster. Clin. Res., 13: 540 (1965).

7. Kraybill, E. N., Sever, J. N., and Avery, G. B., et al.: Experimental use of cytosine arabinoside in congenital cytomegalovirus infection. J. Pediat., 80: 485 (1972).

8. McCracken, G. H., and Luby, J. P.: Cytosine arabinoside in the treatment of cytomegalic inclusion disease. J. Pediat., 80: 488 (1972).

9. Percy, D. H., Albert, D. M., and Amemiya, T.: Ocular defects in newborn rats treated with 5-lododeoxyuridine (IUDR) (37222). Proc. Soc. Exp. Biol. Med., 142: 1272 (1973).

10. Plotkin, S. E., and Steller, H.: Treatment of congenital cy tomegalic inclusion disease with antiviral agents. Antimicrob. Agents Chemother., 9: 372 (1970).

11. Stevens, D. A., Jordan, G. W., and Waddell, T. F., et al.: Adverse effect of cytosine arabinoside on disseminated zoster in a controlled trial. New Engl. J. Med., 289: 873 (1973).

12. Weinstein, L., and Chang, T.: The chemotherapy of virus infections. New Engl. J. Med., 289: 725 (1973).

13. Winick, M., Rosso, P., and Waterlow, J.: Cellular growth of cerebrum, cerebellum and brain stem in normal and marasmic children. Exp. Neurol., 26: 393 (1970).

14. Carworth Farms, New City, N. Y

15. Upjohn Co., Kalamazoo, Mich.

16. This research was supported by the New York City Health Research Council.

17. Requests for reprints should be addressed to: P. A. Brunell, M.D. Department of Pediatrics, New York University School of Medicine, 550 First Ave., New York, N. Y. 10016 (USA).

18. Accepted for publication July $18,1974$. 